\title{
Methods of marketing analysis at all stages of the product life cycle
}

\author{
Svetlana Boronenkova, Anton Chepulyanis", and Svetlana Nikulionok \\ Ural State University of Economics, Yekaterinburg, Russia
}

\begin{abstract}
The paper discusses the essence, and information and methodological support of marketing analysis. We present a method of marketing analysis in accordance with the stages of the product life cycle. Practical application of the marketing analysis methodology using the methods of strategic analysis of matrix and situational modeling is provided.
\end{abstract}

\section{Introduction}

The modern period of economic relations development is characterized by a rapid change in economic conditions with the constant penetration of new goods into the market and an improvement in the quality of products and services. This results in establishing new business conditions and significant changes in the field of management. For effective enterprise management, it is necessary to obtain detailed information about sales in accordance with the type of goods and services, market segments and consumers.

The effectiveness of management is directly related to the quality of its accounting and analytical support, which determines not only the validity of the management decisions taken, but also the need to develop and implement strategic plans. At the same time, traditional accounting does not enable to provide information with the degree of detail required, that is in the context of business processes and operations, business segments, types and groups of products. The historical (retrospective) nature of the information supplied by traditional accounting does not meet the needs of operational management, and does not provide a full-fledged basis for strategic planning, either. Similar objectives are assigned to management accounting and analysis, which do not only cover all the elements of enterprise management, but also take into account the influence of external factors that have a direct impact on the financial and economic activities of the organization.

\section{Essence and Place of Marketing Analysis}

Marketing analysis takes a special place in the system of accounting and analytical support. Marketing analysis is a set of special analytical activities, which aim to provide an objective assessment of the competitive position and place of an organization, as well as its product (product portfolio) in the market, and the consumer demand and supply. Based on the data

\footnotetext{
*Corresponding author: anthonas@yandex.ru
} 
of marketing analysis, the production and sales policy of the company is to be built; an advertising campaign, a plan for promoting and strengthening the competitiveness of the product and organization in the market are to be developed.

The information base for conducting marketing analysis includes both financial and non-financial indicators. It is non-financial information that takes on a special part in its implementation. Marketing research uses a wide range of economic and mathematical, traditional, heuristic and matrix techniques and methods for analysis, as well as factor modeling, comparison, and grouping. Heuristic or multidimensional methods are used when it is necessary to take into account the influence of several factors, but there is a high degree of uncertainty, as well as complexity of the predicted object.

In order to characterize the position of the enterprise in the market, given the existing market situation and opportunities, such modern methods as SWOT analysis, the Boston Consulting Group Matrix (BCG matrix) and the McKinsey Matrix are also used.

\section{Methods of marketing analysis in accordance with the stages of the product life cycle}

For marketing analysis, it is important to study conditions and factors in accordance with the stages of the product life cycle (PLC).

At the first stage of the product life cycle - "the market introduction stage" - resources are absorbed in large volumes, and there is a possibility of unprofitability. The production and sales of goods are growing slowly. Given that the product at this stage is new, difficulties arise both with production and sales; the demand is low, the production is not fully debugged, the distribution channels are only being established. At the same time, the costs of promoting the product are quite high, since the most active and cost-intensive marketing research is to be carried out here, the strategic goal of which is to study the customer's expectations and needs, the main attributes of the product value, as well as to search for a potential market niche, to determine the market capacity and sales dynamics.

If we only consider pricing and costing for product promotion, at this stage one of three marketing strategies is normally used:

- "Skimming the cream off the market quickly": high prices are set and extensive advertising campaigns are conducted with the aim to quickly make a profit per unit of goods;

- "Rapid Market Penetration Strategy": low prices are set and extensive advertising campaigns are conducted to quickly make a profit through large-scale sales; this strategy is feasible if the target audience is price sensitive;

- "Slow Market Penetration Strategy": low prices are set, costs for product promotion are minimal; this strategy is applicable when demand is very price sensitive and the impact of advertising is minimal.

The development of a business plan and the calculation of the break-even point at this stage are aimed at determining the minimum amount of a product, the implementation of which at a certain price per unit will bring the organization the revenue that covers the costs. At this stage, they calculate the critical volume of product sales, evaluate profitability, make comparisons with competitors (benchmarking), and identify the compliance of target and current performance results. The break-even point calculation is especially important when a company introduces a new product to the market. As long as the revenue from the sale of goods is less than the total variable costs, the product will be at the exit stage.

At the second stage of the product life cycle - "the growth stage" - the degree of unprofitable sales decreases and the organization gradually reaches the break-even point. 
From the standpoint of the product life cycle, the end of the introduction phase and a gradual transition to the growth phase can be observed. According to the BCG matrix, this transition is considered as the transformation of "Difficult Children" into "Stars". In order to calculate the balance of material and technical support, the correspondence of production and sales at this stage, the coefficients of rhythm and variation are widely used, and based on the data obtained, the causes of unevenness are identified. To analyze the dynamics and structure of sales, the growth trends, segmentation and diversification of sales channels, the stability of shares and capacity of the product sales market are also to be observed. In this case, the comparison method and factorial modeling are widely used. At this stage, the sales and profit increase significantly, the profitability of products stabilizes, the margins increase, the production develops, and the position of the product and the company in the market is strengthening.

At the next stage of the product life cycle - "the maturity stage" - both sales and profits are stabilized. This stage is characterized as mature in the product life cycle. The production reaches its maximum capacity, so it is important to monitor the deterioration and intensity of the fixed assets use. At this stage, SWOT analysis is widely used as a method of marketing analysis; it identifies the strengths and weaknesses of the product and the strategy of the business as a whole, as well as potential opportunities and threats. SWOT analysis helps determine the further strategy and tactics of maintaining the product on the market. It is at this stage that the organization improves service, after-sales and postwarranty services; it resorts to various methods of sales promotion and consumer motivation: lowering prices and conducting promotions, providing benefits and discounts for brand loyalty. The main goal of marketing at this stage is to maintain the image of the company and the product, and the goals of marketing analysis are to study the competitive environment and to track indicators of profitability and marginality. It is recommended to keep the maturity stage as long as possible in order to obtain stable economic indicators and to further position the product on the market.

The "saturation and decline stage" is the last stage of the product life cycle and is characterized by the cessation of sales growth and a significant price decrease. At this stage, there is a high probability of repeated technological improvement of the product and the technology of its manufacturing. Oftentimes, this stage merges with the stage of maturity, because there is no clear boundary between them. Due to the market saturation and increased competition, the recession stage is characterized by a sharp decline in product sales and, as a consequence, a decrease in production volumes. In order to maintain their market positions, manufacturers invest additional funds in the production modernization in order to improve the quality or reduce the cost of goods, or stop producing non-competitive goods. At the moment when the revenue from the sale reaches the profitability threshold, the product must be discontinued. If a decision is made to withdraw the product from the assortment of goods, the company needs to think about how to do it with the least loss. If the product has a good reputation and distribution channels, it can be sold to another company. If there are no buyers, the manufacturer needs to decide as soon as possible how quickly it is necessary to remove the product from production, how much of the inventories to keep and what to offer in return to former consumers in order to keep their market share at the highest possible level.

\section{Marketing analysis in accordance with the stages of the product life cycle on the example of Philip Morris products}

Let us consider the technology of practical application of marketing analysis in accordance with the product life cycle stages on the example of the tobacco market products. 
The process of reducing the sales volume of tobacco products in Russia began in 2013 after the introduction of the Federal Law "On protecting the health of citizens from the effects of second hand tobacco smoke and the consequences of tobacco consumption" dated 23.02.2013 N 15-FZ. Restrictive measures were introduced on the trade in cigarettes, advertising and subsequently demonstrations of the display of tobacco products at points of sale were prohibited; smoking in public places was prohibited, too. In the first year of the law, the production of tobacco products in Russia fell by more than $5 \%$.

Advertising ban and competition were the main reasons for the revision of manufacturers' views on product promotion, retention of sales volumes and market share. The main focus was on pricing (price containment) and the consumer (changes in the package design and formats). For example, they started to produce "large format" packs, containing 25 cigarettes instead of 20 . Although such packs were more expensive, this format was more profitable per cigarette. Almost all manufacturers released one or several lines of similar products, which positively influenced their sales volumes. But from June 1, 2016, the government imposed a ban on this format of packs.

At the same time, the Government of the Russian Federation set a course to increase excise taxes on tobacco products. To date, the price per pack for some brands has increased by more than $80 \%$. The increase in prices has had a very strong impact on sales in various price segments - the premium segment has noticeably decreased, and, at the same time, the segment of low-price offers has grown significantly and is still growing. Today, all tobacco manufacturers have a price offer of 70-75 rubles per pack, and despite the fact that the sale of such products does not bring high profits, this segment is very important from the perspective of maintaining the market share.

The production and distribution of alternative products (electronic cigarettes, vapes) also significantly affect the tobacco market. The lack of legislative regulation leads to the situation when many smokers give up cigarettes in favor of such products.

The influence of cheap counterfeit products from Kazakhstan and Belarus should be particularly stressed. From 2016 to 2017, the amount of counterfeit goods increased by more than 1.5 times; according to the research, illegal goods can be found in every tenth retail outlet in Russia.

In 2018, the tobacco market also continued to fall, new legislative restrictions on the sale and distribution of tobacco products were introduced, and excise taxes were raised again.

The tobacco market in Russia is oligopolistic and is represented by three largest transnational manufacturers - JTI, BAT and Philip Morris, which account for more than $80 \%$ of the total production and sales of tobacco products. 
The largest tobacco companies in Russia by sales volume (market share, \%), Source: NIELSEN analytical

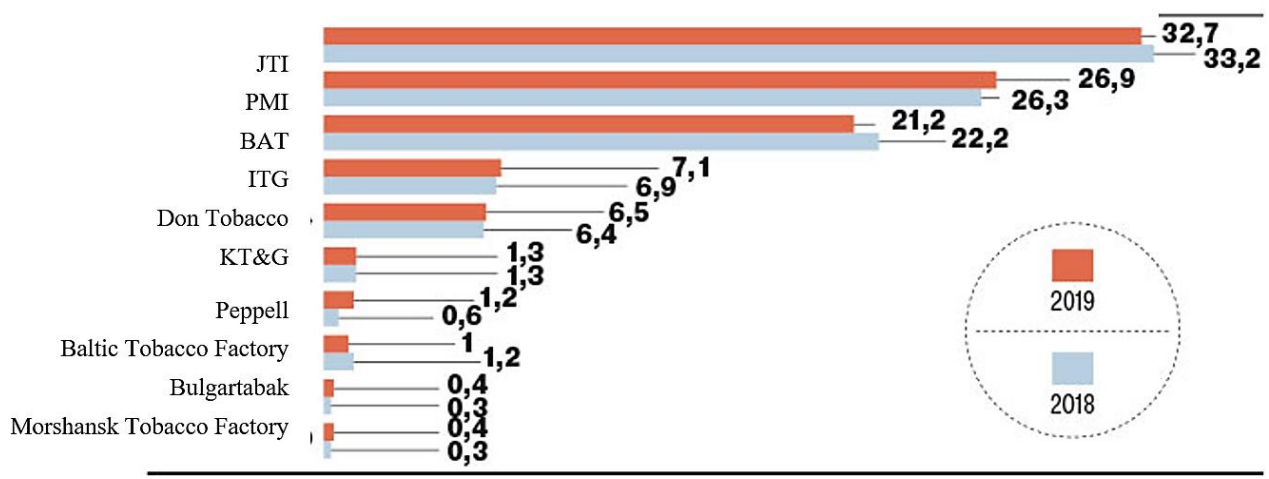

Fig. 1. The tobacco market structure in $2018-2019$

Based on the marketing research of the Nielsen analytical agency [7], all adult smokers can be split into two groups - those who prefer to save money and choose low-price cigarettes and those who do not save and smoke premium cigarettes. In the low-price segment, the main brands in the Russian market are Philip Morris (PMI manufacturer), Royals (BAT manufacturer), Parker and Simpson (Imperial Tobacco Group manufacturer).

Philip Morris Sales \& Marketing LLC (PMSM LLC) is part of the Philip Morris International (PMI) group, one of the largest tobacco companies in Russia; it supports the marketing of Philip Morris International cigarette brands. The company's key brands are Parliament in the premium segment, Bond Street in the mid-priced segment, and Philip Morris in the low-priced segment.

The brand portfolio analysis by method of the Boston Consulting Group (BCG) matrix is shown in Figure 2.

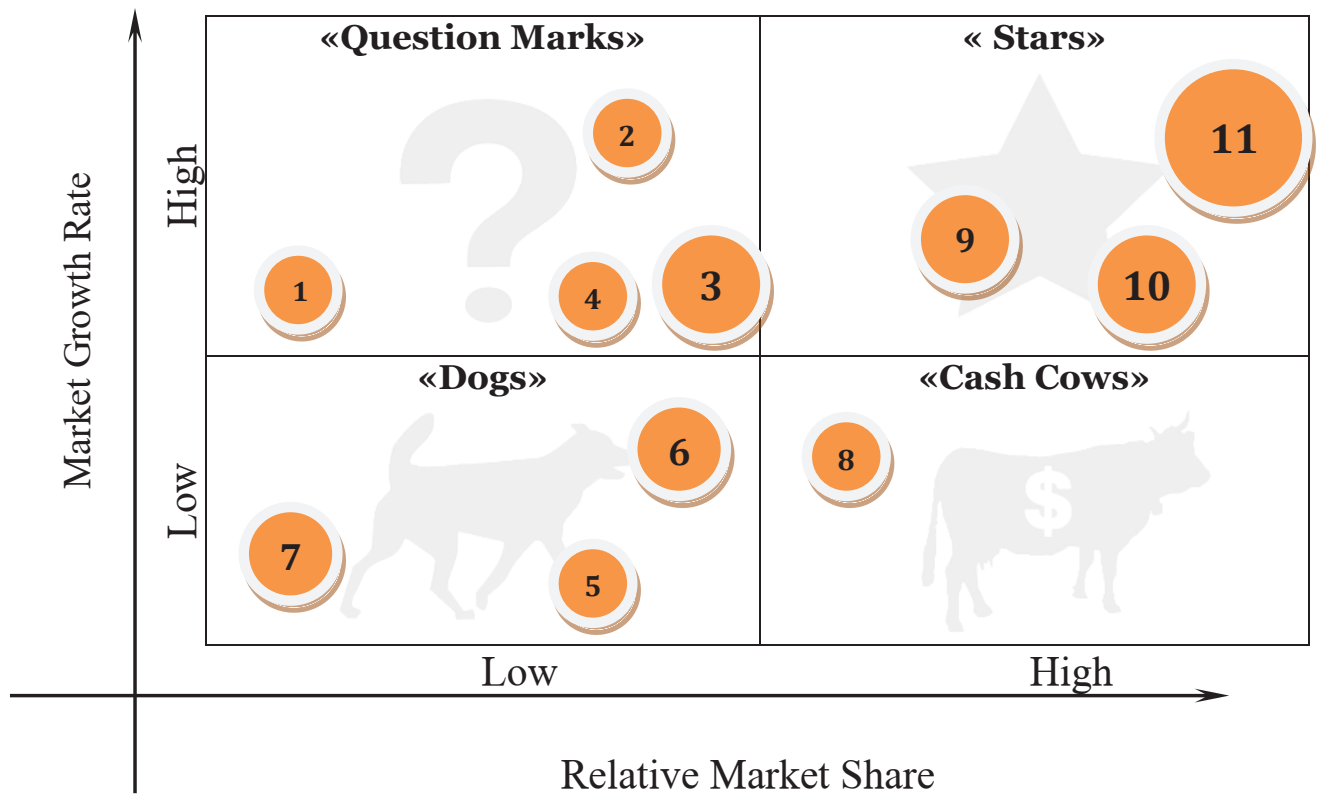


«Question Marks»

(1) EVE

(2) CHESTERFIELD

(3) L\&M

(4) MARLBORO

(5) APOLLO-SOYUZ

(6) OPTIMA

(7) PRESIDENT $\ll \mathbf{S t a r s} »$

(9) NEXT

(10) BOND STREET

(11) PHILIP MORRIS

«Dogs»

(8) PARLIAMENT

Fig. 2. Analysis of the PMSM LLC brands using the BCG matrix

Three of the company's brands are in the "Stars" category - Philip Morris, Next and Bond Street. With a sufficient level of investment, these brands are capable of providing sustainable revenue growth for the company.

Analysis of these brands in terms of the product life cycle stages showed the following. At the end of 2017, at the stage of introduction of Philip Morris into the market (the first stage of the product life cycle), there was a significant absorption of resources. Given that the brand was new, there were difficulties with production, and advertising costs were quite high. To promote the new Philip Morris product, the strategy of rapid market penetration was used, which, as it has been mentioned above, suggests low prices and an extensive advertising campaign to quickly maximize profits through large-scale sales.

At the stage of growth in demand for the Philip Morris product, the highest dynamics of sales and profits can be traced, the production is developing and the product's position in the market is strengthening. Today, the Philip Morris brand is one of the fastest growing brands in the company's portfolio and the most promising, too. The success of this brand is due to a well-thought-out marketing strategy, which was based on 5 growth drivers:

- $\quad$ the brand had sources of growth due to a wide distribution;

- presence of a low-budget target audience;

- the share of consumers could be increased;

- a competitive advantage was created due to a fairly low price compared to the prices set by competitors;

- the company had the resources to make large-scale investments in the product promotion.

Thus, the strategy of marketing and marketing analysis was aimed at quickly capturing the market and its large-scale expansion.

Bond Street and Next products are also "Stars" in terms of the BCG Matrix, however, they are at the next stage of the life cycle - product maturity stage, as they show stable sales and profit. However, due to tougher competition, a recession phase may occur, which is why it is recommended that the maturity phase for the Bond Street and Next brands should be extended, as it ensures the stability of financial and economic indicators.

The premium brand Parliament is a "Cash Cow" according to the BCG matrix; from the perspective of the product life cycle, it is also at the maturity stage. It is recommended that this brand should maintain the current level of sales and investments in the amount necessary to maintain their market share.

Apollo-Soyuz, Optima and President had low market shares and were not promising. These brands are in the "Dogs" segment of the BCG matrix. The strategy for this category is to maximize income with minimal investment and then remove the product from the company's product portfolio. From the perspective of the product life cycle, these brands are in decline. In 2018, the company made a decision to gradually withdraw President and 
Apollo-Soyuz products from the assortment with minimal losses; investments in these brands completely ceased and the products were discontinued. The Optima brand in its turn had a good reputation and distribution channels, so the company decided to merge the Optima brand with Philip Morris in order to keep their market share at the highest possible level.

Eve, L\&M, Marlboro and Chesterfield products are promising SCUs with a high degree of uncertainty and need significant investments so as to increase the market share. At the same time, investments in the "Question marks" segment are associated with a high level of risk and uncertainty, therefore, it is not recommended that a large share of funds should be used for their development. If we consider these brands from the perspective of the product lifecycle, they are at the stage of maturity and the company needs to invest in them so that they do not go into the decline stage.

To assess the strategic positions in the tobacco market, we carried out a SWOT analysis for PMSM LLC, which enabled to assess the external and internal environment of the company, affecting its development as a whole and its assortment policy in particular.

Table 1. SWOT analysis for PMSM LLC

\begin{tabular}{|c|c|}
\hline Strengths & Weaknesses \\
\hline $\begin{array}{l}\text { - Included in the circle of oligopolists of the } \\
\text { tobacco market, the key market share } \\
\text { - A well-thought-out strategy and a clear mission in } \\
\text { the market, a developed corporate culture; } \\
\text { - Diversified and segmented assortment policy, } \\
\text { adjusting to consumer demand; } \\
\text { - Flexible cost and pricing; } \\
-\quad \text { Customer loyalty; } \\
-\quad \text { Strong brand portfolio and image brands; } \\
-\quad \text { Stable distribution channels; } \\
-\quad \text { Effective partnership in foreign markets; } \\
-\quad \text { High rate of innovation in manufacturing. }\end{array}$ & $\begin{array}{l}\text { - General harm of tobacco smoking to } \\
\text { human health; } \\
- \text { The presence of weak brands; } \\
-\quad \text { Underdevelopment of alternative } \\
\text { channels of communication with } \\
\text { consumers and the public. }\end{array}$ \\
\hline Opportunities & Threats \\
\hline $\begin{array}{l}\text { - The company invests heavily in the development } \\
\text { of innovations that have the potential to significantly } \\
\text { reduce the risk of smoking-related diseases; } \\
\text { - Charity programs and corporate volunteering; } \\
\text { - Products undergo regular quality control based on } \\
\text { more than } 250 \text { parameters; } \\
\text { - Availability of a supply chain management } \\
\text { system, which reduces transaction costs; } \\
\text { - Development and market launch of a new line of } \\
\text { smokeless tobacco products; } \\
\text { - Effective accounting, analysis and management of } \\
\text { financial and non-financial indicators of the } \\
\text { company's sustainable development. }\end{array}$ & $\begin{array}{l}\text { - Availability of alternative products } \\
\text { (vapes, electronic cigarettes); } \\
-\quad \text { Counterfeit products; } \\
\text { - Falling real incomes of the population } \\
\text { and slowing consumer demand; } \\
-\quad \text { Active anti-smoking campaign, } \\
\text { propaganda of a healthy lifestyle; } \\
-\quad \text { Rising prices for raw materials; } \\
-\quad \text { Tightening of tobacco legislation; } \\
-\quad \text { Progressive growth of excise taxes on } \\
\text { tobacco products; } \\
-\quad \text { The competitors, successful } \\
\text { marketing }\end{array}$ \\
\hline
\end{tabular}

\section{Conclusions}

Thus, the marketing analysis of consumers, assortment and distribution channels, structure and sales volume, calculated for each stage of the product life cycle, enables us to identify the current stage of both the product and the company as a whole, as well as the marketing strategies and methods of analysis to be applied in order to maximize the company profits. 


\section{References}

1. S.A. Borenenkova, A.V. Chepulyanis, Theoretical and methodological foundations of strategic accounting and analysis costs, 248 (2017)

2. V.E. Kerimov, Strategic accounting, 168 (2010)

3. F. Kotler, Marketing Basics, 526 (2016)

4. Zhan-Zhak Lamben, Strategicheskiy marketing, 345 (2016)

5. K. Uord, Strategic management accounting, 448 (2016)

6. A.N. Khorin, V.E. Kerimov, Strategic analysis, 345 (2016)

7. Official site of The Nielsen Companies, https://www.nielsen.com

8. Report on the activities in the field of sustainable development of affiliated companies "PHILIP MORRIS INTERNATIONAL" IN RUSSIA for 2019 , https://www.pmi.com/ 